Abstract P276 Table 1 MIC range, MIC 50, MIC 90 and\% resistant P.aeruginosa isolates for Cystic Fibrosis (CF), Non Cystic Fibrosis Bronchiectasis (NCFB) and controls (C)

\begin{tabular}{|c|c|c|c|c|c|c|c|c|c|c|c|c|c|c|c|c|c|c|}
\hline & \multicolumn{3}{|c|}{ Meropenem } & \multicolumn{3}{|c|}{ Ceftazidime } & \multicolumn{3}{|c|}{ Ticarcillin } & \multicolumn{3}{|c|}{ Temecillin } & \multicolumn{3}{|c|}{ Siprofloxacin } & \multicolumn{3}{|c|}{ Gentamicin } \\
\hline & CF & NCFB & C & CF & NCFB & C & CF & NCFB & C & CF & NCFB & C & CF & NCFB & C & CF & NCFB & C \\
\hline $\begin{array}{l}\text { MIC } \\
\text { Range }\end{array}$ & $\begin{array}{l}0.008- \\
16\end{array}$ & $\begin{array}{c}0.008- \\
32\end{array}$ & $\begin{array}{c}0.008- \\
8\end{array}$ & $\begin{array}{l}0.25- \\
128\end{array}$ & $\begin{array}{l}0.125 \\
-64\end{array}$ & $2-16$ & $\begin{array}{l}0.125- \\
128\end{array}$ & $\begin{array}{l}0.125 \\
-16\end{array}$ & $\begin{array}{l}16- \\
128\end{array}$ & $\begin{array}{l}0.5- \\
128\end{array}$ & $\begin{array}{l}0.064 \\
-128\end{array}$ & $8-128$ & $\begin{array}{l}0.03- \\
16\end{array}$ & $\begin{array}{c}0.032- \\
32\end{array}$ & $\begin{array}{l}0.03- \\
4\end{array}$ & $1-64$ & $\begin{array}{l}0.032- \\
4\end{array}$ & $0.25-4$ \\
\hline MIC 50 & 0.5 & 0.125 & 0.125 & 4 & 1.5 & 4 & 8 & 1 & 32 & 8 & 4 & 128 & 1 & 0.25 & 0.06 & 2 & 0.25 & 1 \\
\hline MIC 90 & 4 & 4 & 1 & 128 & 8 & 16 & 128 & 128 & 128 & 128 & 128 & 128 & 4 & 32 & 0.5 & 64 & 2 & 2 \\
\hline $\begin{array}{l}\% \\
\text { Resistant }\end{array}$ & $21 \%$ & $18 \%$ & $6 \%$ & $28 \%$ & $12 \%$ & $16 \%$ & $36 \%$ & $18 \%$ & $74 \%$ & NA & NA & NA & $63 \%$ & $47 \%$ & $7 \%$ & $32 \%$ & $0 \%$ & $0 \%$ \\
\hline $\begin{array}{l}\% \\
\text { Sensitive }\end{array}$ & $79 \%$ & $82 \%$ & $94 \%$ & $72 \%$ & $88 \%$ & $84 \%$ & $64 \%$ & $82 \%$ & $26 \%$ & NA & NA & NA & $37 \%$ & $53 \%$ & $93 \%$ & $68 \%$ & $100 \%$ & $100 \%$ \\
\hline $\begin{array}{l}\text { EUCAST } \\
\text { BP }\end{array}$ & & $S \leq 2, R>8$ & & & $3 \leq 8, R>8$ & & & $16, R>1$ & & & NA & & & $\leq 0.5, R>1$ & & & $S \leq 4, R>4$ & \\
\hline
\end{tabular}

Therefore, temocillin may provide a useful alternative to the current anti-pseudomonal antibiotics in treating NCFB and CF patients. prognosis and 5 year mortality risk can be estimated from a lung function test widely available and frequently performed as opposed to CPET which is only available in specialist centres.

\section{P277 PHYSIOLOGICAL RESPONSE TO EXERCISE IN AN ADULT CYSTIC FIBROSIS POPULATION: INVESTIGATING THE RELATIONSHIP BETWEEN HRR AT ANAEROBIC THRESHOLD AND FEV1\% PREDICTED}

G Comber. Royal Wolverhampton NHS Trust, Wolverhampton, UK

\subsection{6/thoraxjnl-2015-207770.413}

Introduction Cystic Fibrosis (CF) is an autosomal, recessive disease characterised by a mutation or dysfunction. Patients suffer a number of complications caused by poor sodium and chloride transport across cell membranes leading to viscous secretions. The disease is life limiting and around $85 \%$ of these early deaths are a result of respiratory failure with the most accurate prognosis marker being maximum volume of oxygen utilisation $\left(\mathrm{VO}_{2}\right.$ max $)$. This parameter is affected by a number of factors and can be increased or preserved through correct exercise prescription. For maximal benefits exercise should be targeted around anaerobic threshold however this is not easily identifiable during regular activities.

Method 15 patients with CF underwent Cardiopulmonary exercise testing (CPET) to establish whether there was a significant correlation between Forced Expiratory Volume in one second percent predicted $\left(\mathrm{FEV}^{1} \%\right)$ and Heart Rate Reserve (HRR) at Anaerobic Threshold (AT) as a method of giving an easily monitored parameter (Heart Rate) as a target during exercise, for a given severity of lung disease, to gain maximal benefits from the activity.

Results The correlation between $\mathrm{FEV}^{1} \%$ and HRR at AT was found to be very weak, $r(13)=0.269, p>0.05$ however there was a strong correlation between FEV1\% and Maximum volume of utilised oxygen percent Predicted $\left(\mathrm{VO}_{2} \max \%\right)$, $\mathrm{r}(13)=0.601, \mathrm{p}<0.05$.

Discussion This study shows that $\mathrm{FEV}^{1} \%$ can not be used as a predictor of HRR at AT, however the lack of correlation does show a narrow window for HRR in which patients with CF should aim in order to exercise near AT and ultimately improve their fitness and prognosis. The strong correlation between $\mathrm{FEV}^{1} \%$ and $\mathrm{VO}_{2}$ max $\%$ serves a great purpose in the that

\section{P278 IS THERE A ROLE FOR TELEMEDICINE IN CYSTIC FIBROSIS? A SYSTEMATIC REVIEW}

${ }^{1} \mathrm{R}$ Curley, ${ }^{2} \mathrm{ZH}$ Hoo, ${ }^{2} \mathrm{R}$ Archer, ${ }^{1} \mathrm{MJ}$ Wildman. ${ }^{1}$ Adult CF Centre, Northern General Hospital, Sheffield, UK; ${ }^{2}$ SCHARR, University of Sheffield, Sheffield, UK

\subsection{6/thoraxjnl-2015-207770.414}

Background As a result of new medical advances people with $\mathrm{CF}$ are now able to live longer but still require frequent specialist care input and support. To cope with an ever increasing complex condition and demand for care, CF centres are having to rethink the way they work. Telemedicine is an evolving field which has the advantage of remote monitoring and real time review and may provide a solution.

Objectives To determine whether telemedicine has a role in the management of CF in terms of: 1) Feasibility and acceptability, 2) Early pulmonary exacerbation detection, and 3) Self-management and improving adherence to prescribed therapies.

Methods A systematic search was undertaken to identify relevant studies. This involved seven electronic databases, the top four peer reviewed journals reporting on $\mathrm{CF}$ and telemedicine, and the three major conference proceedings in $\mathrm{CF}$ and telemedicine. Clinical trial registers were searched to find ongoing studies as supplementary evidence. A mixed methods synthesis was performed to combine results from quantitative and qualitative studies.

Results 34 studies in total were included in the results synthesis. These consisted of mainly small pilot and feasibility studies. There were 7 RCTs largely reporting interim results rather than efficacy data. Rates of adherence to telemedicine varied between 10.16 to $59 \%$ but were generally poor with barriers including frequent measures being a burden, forgetting, and denial of results. There was a general consensus that pulmonary exacerbations can be detected early but no statistical tests of significance performed. There were also only 2 studies predominantly reporting qualitative evidence. After corroborating the results using thematic synthesis this led to 3 main themes (expectations, technical aspects, and impacts of telemedicine) linked to these were barriers and facilitators. 